\title{
JAVIER PÉREZ DE CUÉLLAR: UNA VIDA DEDICADA AL PERÚ Y A LA DIPLOMACIA
}

Manuel Rodríguez Cuadros*

Javier Pérez de Cuéllar ha fallecido. A los cien años. Como si en el simbolismo del siglo hubiese querido expresar su filiación y fe por un país milenario. El Perú. La patria de sus desvelos, sueños y realizaciones. En lo profesional Pérez de Cuéllar fue un devoto de la patria. Un diplomático al servicio de la Nación. En lo personal, un hombre amante de la literatura. Con una sensibilidad humana aguda. Expresada siempre en la mesura del juicio justo o el pensamiento equilibrado. Un liberal - social de pensamiento y obra. Sus actos oficiales y cotidianos siempre estuvieron signados por el respeto al otro. Aún en la crítica. Tenía la virtud diplomática de tomar una distancia de los hechos. Lo que le permitía el análisis y el juicio objetivo. Esencial para las decisiones políticas. La diplomacia es política entre Estados. Y en esa visión objetivada de la realidad, siempre preservó y cultivó una línea de naturaleza ética. Nunca una decisión contraria al derecho internacional. Jamás alguna otra contraria a la democracia o los derechos humanos.

Javier Pérez de Cuéllar ingresó al Ministerio de Relaciones Exteriores en 1940. En esa época, en el Perú, la dualidad campo-ciudad escondía aún las fracturas de la vida peruana. Y la democracia era una ucronía que sólo podía leerse en constituciones republicanas casi nunca aplicadas.

En el mundo, la violencia se generalizaba con la segunda guerra mundial. Las conciencias libres aprendían que frente al fascismo y al nacional socialismo, había que oponer las ideas y los valores de la democracia. En ese mundo inició Javier Pérez de Cuéllar su carrera diplomática. Y seguramente esas circunstancias abonaron sus sentimientos a favor de la libertad, la democracia y el respeto al otro.

Veintidós años después, luego de haber servido en Lima, Francia, Inglaterra, Bolivia y Brasil, accedió al grado de Embajador del Servicio Diplomático de la República. Cuatro años más tarde asumió la jefatura del Servicio Diplomático como Secretario General de la Cancillería. En 1979 fue nombrado Secretario General Adjunto de las Naciones Unidas para Asuntos Políticos Especiales. Tres años más tarde, el 15 de diciembre de 1981 fue electo, por unanimidad, Secretario General de las Naciones Unidas. Y reelecto el 19 de octubre de 1986.

La historia posterior está más cerca de nosotros. Su filiación por el Perú y por la democracia lo condujeron a asumir la responsabilidad de representar a la conciencia democrática del país, en las elecciones de 1995, enfrentando a la dictadura. El año 2000, restaurada la democracia, por la acción cohesionada en uno de los escasos momentos de

\footnotetext{
* Diplomático y docente. Miembro Titular y del Consejo de Honor de la Sociedad Peruana de Derecho Internacional.

Artículo publicado en el Diario La República, el 6 de marzo de 2020. Disponible en: https://larepublica.pe/politica/2020/03/06/javier-perez-de-cuellar-una-vida-dedicada-al-peru-y-a-ladiplomacia/
} 
responsabilidad y conciencia democrática en la historia del país, asumió la Cancillería y la Presidencia del Consejo de Ministros en el gobierno constitucional de transición de Valentín Paniagua.

Aludiendo a la memoria, Schopenhauer señalaba que "la verdadera salud del espíritu consistía en la perfección del recuerdo". Recordar a Pérez de Cuéllar es hacer memoria, también, de su gestión como Secretario General de las Naciones Unidas.

En esa salud de espíritu, recordemos que, cuando asumió la Secretaría General, en enero de 1982, el mundo, con asombro y pesar, observaba cómo la lógica del conflicto se agudizaba peligrosamente.

En abril se inició la guerra de Las Malvinas. En junio la cumbre industrializada de Versalles fracasó en su intento de definir una estrategia económica común frente al Este. Casi simultáneamente Israel atacó el Líbano. Irán e Irak seguían escalando en la guerra. En noviembre, Andropov rechazó la propuesta americana de "opción cero". Su contrapropuesta para disminuir el $25 \%$ de los misiles intercontinentales corrió la misma suerte por parte de Washington. En marzo del 83, el presidente Reagan lanzó la Iniciativa de Defensa Estratégica. Y asumió una posición crítica sobre las negociaciones SALT II, que Carter había impulsado. La lucha ideológica recrudeció. El diálogo Este-Oeste se fue tornando en sólo un recuerdo. El inmovilismo se afianzaba. La desconfianza reaparecía. En París, "Le Monde" alertaba contra el resurgimiento de la guerra fría.

En el ámbito económico el problema de la deuda estallaba. El Norte y el Sur constataban en Cancún la imposibilidad del diálogo. América Latina iniciaba su costoso recorrido por la década perdida.

Las Naciones Unidas se aprestaban a enfrentar una de las más grandes tensiones de su historia. Desconfianza de los centros de poder mundial. Insatisfacción de las aspiraciones de los países en desarrollo. Carencias presupuestarias cada vez más ostensibles. Élites y grupos de presión que inducían al aislacionismo para vaciar o minimizar su agenda. Los EEUU redujeron su cuota. La crisis se aceleró.

En 1985, Maurice Bertrand en "L'Etat du Monde” sintetizó la situación: "la ONU, en definitiva, aparece sólo como un foro de propaganda... nadie sabe todavía qué tipos de reforma podría dar mayor utilidad a la organización y el escepticismo continúa prevaleciendo sobre la posibilidad misma de esa reforma”.

Seis años después, avanzada la gestión de Pérez de Cuéllar en la Secretaría General, el mismo Maurice Betrand constató el éxito de una diplomacia que produjo el cambio. Bajo la sabia fórmula de cambiar sin alterar drásticamente los equilibrios. Una diplomacia al decir de Francois Miterrand, de "force tranquile".

En la edición del L'Etat du Monde de 1989, Bertrand escribió: “desde 1988, la Organización de las Naciones Unidas y su Secretario General, Javier Pérez de Cuéllar, gozan de una sostenida popularidad: el papel jugado por la organización en la resolución de los conflictos regionales ha ganado la primera página de la prensa internacional; las 
fuerzas para el mantenimiento de la paz de la ONU han obtenido el Premio Nóbel de la Paz".

\section{¿Cómo explicar este cambio en la situación?}

El hilo de la respuesta se encuentra en una de las ideas centrales que Pérez de Cuéllar desarrolló en su Memoria del año 1991. "El renacimiento de la organización ha reflejado un cambio cualitativo, tanto de actitudes como de percepciones. Es, además, resultado de la activa cooperación de los Estados miembros y de largos preparativos y arduos esfuerzos de la Secretaría en circunstancias desalentadoras. Se originó hace algunos años, cuando en la cambiante atmósfera internacional comenzaron a vislumbrarse oportunidades de adoptar medidas de mantenimiento de la paz. Son clarísimas las diferencias entre la situación sobre la que informo hoy y la que di a conocer en mi primera memoria anual".

Efectivamente, las Naciones Unidas pasaron, al ritmo de los cambios mundiales y de la acción responsable, imaginativa, eficiente y versátil del Secretario General, de un estado de erosión de su autoridad institucional y prestigio a la situación en la que ejerció, por primera vez en la historia, de manera legítima, las facultades que le otorgó la Carta de San Francisco.

La seguridad colectiva, como sistema de mantenimiento de la paz, había fracasado en la Sociedad de las Naciones. Desde 1945, las Naciones Unidas reprodujeron esta misma frustración. La estructura de la guerra fría y el bloquismo inhibieron, a través del veto, todas las potencialidades del Consejo. Nunca funcionó conforme a las previsiones de la Carta.

A inicios de los años 90, Pérez de Cuéllar obtuvo que, después de 46 años, el Consejo de Seguridad funcione con legitimidad y eficacia. Lamentablemente, con posterioridad a su gestión, los problemas de disfuncionalidad de las Naciones Unidas han vuelto a emerger. Con mayor gravedad.

Con aguda sensibilidad respecto del curso de los acontecimientos mundiales, Javier Pérez de Cuéllar inició, adelantándose a los hechos, una revisión de la función y de los procedimientos de acción del Consejo de Seguridad. A partir de 1987, propició, en ese sentido, una coordinación especial entre el Secretario General y el Consejo. Asumiendo, con tino y firmeza, plenamente las facultades que le otorgaba la Carta, tanto en el ámbito administrativo como en el político.

Ejerció con relevantes resultados una de sus convicciones, guardadas en el recato de una proverbial humildad. La de saber que un diplomático por más alto cargo que desempeñe, incluido el de Secretario General de las Naciones Unidas, no ejerce poder por sí mismo, sino por delegación. En la diplomacia, el poder lo tienen los Estados. Y por más alta que sea la jerarquía de un negociador -y el Secretario General de las Naciones Unidas lo es- nunca puede confundirse el poder delegado por los Estados con el poder del Estado. 
Por el contrario, la diplomacia de la paz y de la negociación supone diferenciar la "potestas", el poder de los Estados, de la "autoritas" del diplomático o el negociador. Para construir la paz hay que ejercer con decisión, cordura, humildad, creatividad y firmeza la "autoritas" del negociador para inducir un realineamiento de la "potestas" de los Estados, a favor de la paz, la estabilidad, el equilibrio y el beneficio mutuo.

Pérez de Cuéllar logró el cambio delineando nuevos equilibrios en el poder mundial. Obtuvo, en el contexto de una situación de crisis, una relación consensual entre el Consejo de Seguridad y el Secretario General. Y lo hizo en la direccionalidad del cambio, la afirmación de la paz, y la promoción de la democracia y los derechos humanos.

A la obtención de la paz entre Irán e Irak se sumaron, como un efecto dominó, los Convenios de Ginebra que pusieron fin a la intervención soviética en Afganistán; la independencia de Namibia; la paz negociada en Angola, el control de la situación en Centroamérica y la paz entre el gobierno salvadoreño y el frente Farabundo Martí para la Liberación Nacional. Al mismo tiempo, se prosiguió con las negociaciones para lograr soluciones pacíficas en el Sahara Occidental, Kampuchea, Chipre e incluso el Medio Oriente.

Sin embargo, la cuestión de la intervención aliada para cesar la ocupación iraquí en Kuwait puso a prueba todo el emergente mecanismo de seguridad colectiva. La situación no estuvo exenta de problemas. Pérez de Cuéllar fue claro. La acción aliada, señaló, era una ofensiva legal, más no de las Naciones Unidas. La diplomacia de la serenidad, la preservación del derecho internacional y la cautela razonada en el manejo de escenarios y variables de concertación, logró superar los escollos. Restablecida la paz, las Naciones Unidas asumieron responsabilidades definidas en la ejecución de los acuerdos de cese del fuego.

Estos cursos de acción otorgaron a la organización mundial nuevas y complejas responsabilidades. Desde acciones para regular la independencia de un país (Namibia) hasta el monitoreo de un referéndum de autodeterminación (Sahara Occidental), pasando por la supervisión de elecciones libres (Nicaragua y Haití), la asistencia humanitaria a la población kurda en Irak, o el mantenimiento del grupo de observadores militares que supervisó el cese del fuego entre India y Pakistán. El propio Secretario General definió este amplio abanico de actividades como "tareas de una complejidad y un alcance nunca antes puestos a prueba".

A Javier Pérez de Cuéllar le ha correspondido la tarea histórica de dar respuesta afirmativa a las dos interrogantes, que siempre se utilizaron para criticar a las Naciones Unidas. ¿Pueden las Naciones Unidas reunir las facultades necesarias para restablecer la paz quebrantada y anular los actos de agresión? ¿Tiene la capacidad y los medios para ejecutar proyectos de paz, complejos y cambiantes? Durante casi cinco décadas la respuesta fue no. La gestión de Pérez de Cuéllar respondió que sí. Ello nos da fundadas esperanzas que el actual proceso de reforma pueda retomar el curso del mantenimiento de la paz eficaz, sustentado en el multilateralismo y el derecho internacional.

Pero la gestión de Pérez de Cuéllar no se constriñó al peregrinaje por la paz, como bien se han titulado sus memorias. Reconoció que las relaciones internacionales no se 
agotan en la vida de relación entre los Estados. Señaló que la interdependencia compleja de nuestros días presenta nuevos desafíos de cooperación y conflicto. Sostuvo que el medio ambiente, los derechos humanos y la pobreza son de prioritaria atención, en una concepción humana de la paz. Como lo son también aquellas realidades emergentes a las que Pérez de Cuéllar caracterizó en su gestión como expresiones del "disloque y desajuste social": el narcotráfico, el tráfico de armas, la toma de rehenes y el terrorismo.

Un estadista tiene la enorme responsabilidad de obtener o preservar la paz y el bienestar de su pueblo. El Secretario General de las Naciones Unidas tiene como su pueblo a los pueblos del mundo. Pérez de Cuéllar así lo comprendió y fue un certero constructor de la paz, un constante promotor de la democracia y el respeto a la dignidad del ser humano.

Al mismo tiempo, trabajó por un mundo más equitativo, aun en las relaciones de poder. Alertó, con razón, sobre los peligros de que la mundialización incremente las asimetrías: "En esta época de profunda transición es menester obrar con extraordinario cuidado para evitar un desequilibrio en la gestión de los asuntos internacionales por parte de las Naciones Unidas. Apenas si puede invocarse el concepto tradicional de equilibrio de poder en una situación en la que las capacidades económicas y tecnológicas y su desigual distribución, se han convertido en factores críticos y a menudo decisivos".

Hace unos años, Mario Vargas Llosa, en un homenaje a Javier Pérez de Cuellar, en la Universidad de Lima, señaló que la apuesta afirmativa por el futuro del Perú se encarna, en cada generación, en peruanos cuya trayectoria profesional, creativa y cívica enorgullecería a cualquier sociedad porque han dejado una marca de excelencia en nuestro tiempo.

Jorge Basadre, a su vez, nos ha recordado que la más alta jerarquía entre los peruanos corresponde a quienes han contribuido a realizar al Perú en su vida y en su obra. Y nos ha indicado, también, que la credencial de esta categoría de hombres y mujeres de la patria, es nada más y nada menos que una trayectoria en la que vida y obra tengan por referente dos límites: nada más que el Perú y nada menos que el Perú.

Javier Pérez de Cuéllar encarnó la vida y la obra que Mario Vargas Llosa y Jorge Basadre asignan a los constructores del Perú como Estado y como nación, como utopía y como realidad. 